\title{
Low-temperature ground freezing methods for underground construction in urban areas
}

\author{
Petr Nikolaev ${ }^{1, *}$ and Mikhail Shuplik ${ }^{1}$ \\ ${ }^{1}$ National University of Science and Technology MISIS, 119991 Moscow, Russia
}

\begin{abstract}
Artificial ground freezing (AGF) is a commonly used ground improvement technique. It can be applied in diverse construction projects in dense populated urban areas where other methods are inapplicable. In this article are discussed several methods of ground freezing, such as: "brine" freezing, liquid nitrogen freezing, solid carbon dioxide freezing. Their advantages and disadvantages are indicated. For solid carbon dioxide freezing, several approaches are presented. One of them is a brine "aftercooling" freezing method. They can significantly increase efficiency of ground freezing and reduce its cost.
\end{abstract}

\section{Introduction}

Modern cities need a large number of underground facilities: subway; transport tunnels; sewers, etc. With each passing year, the demand of their number increases. However, the amount of available underground space with good hydrogeological conditions is very limited. Therefore, new projects have to be designed at greater depth, in more complex geological environment. According to the analysis of hydrogeological conditions of Moscow [1], the majority of soils at the more than $20 \mathrm{~m}$ depths are fully saturated and unstable. In such conditions, it is necessary to pay special attention to the selection of a ground improving method, which makes possible the safety of construction works.

There are several methods for improving ground properties, such as ground water lowering, grouting (chemical, cement etc.), and artificial ground freezing (AGF) [2,3]. The most universal of them is AGF. It works in any soils, in any hydrological conditions. In terms of environmental safety, this method has significant advantages - its influence on soils and groundwater is temporary and local. After workflow, the soils return to their original state, that is significant for their further usage [4].

\section{AGF in urban construction}

Artificial ground freezing method was proposed in $19^{\text {th }}$ century in the mining industry [5]. Since that time, the application field of this method became wider. Nowadays, this method is regularly used for construction works in urban areas. For example, it was applied during underground construction in New York [6], Nanjing [7], Napoli [8], Moscow [9] etc.

\footnotetext{
*Corresponding author: pvnikolaev@ misis.ru
} 


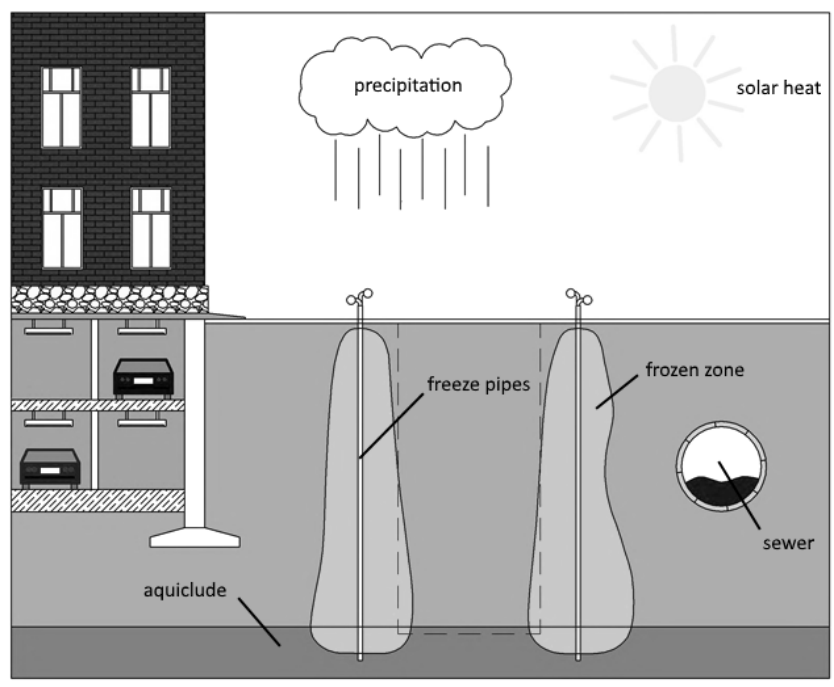

Fig. 1. Ground freezing in urban underground space

AGF in urban underground space has several distinctive features.

First, the amount of frozen soils is relatively small and/or it locates close to the ground surface, as a result, the influence of solar heat and precipitations is significant (for example, see [10]). The design of freezing under such condition needs taking into account the heat flux from the atmosphere, that can be described, for instance, by similarity theory methods (see, for example [11]).

Secondly, underground facilities with high temperature (e.g. existing tunnels, sewage collectors, heat distribution networks etc.) may be located near a freeze zone (for example see [12]).

Thirdly, the soils and groundwater that were affected by human activity are not homogeneous and contaminated by salts and petroleum products. It leads to increasing filtration rate and decreasing freezing temperature of water. Within this framework, the shape of the ice-wall became irregular (Fig. 1), thus a cofferdam may be not created.

If seepage flow velocities or heat flow from heat sources around frozen area is high, a state of thermal equilibrium could be set. This may aggravate the closure of the freezing body.

For intensifying AGF in such conditions, several methods were proposed. An interesting modern approach is using advance design methods, which include mathematical optimization of freezing parameters (see, for example $[13,14]$ ), such as the location of freezing pipes and their diameters. However, these methods are still under developing. The classical approach is decreasing the temperature of freeze pipes' walls. This is achieved by increasing the power of a freezing plant or by choosing another freezing method.

\section{AGF methods}

There are two main groups of AGF techniques [15]:

- with a refrigeration plant and pumped loop secondary coolant ("brine" freezing method);

- $\quad$ with an expendable refrigerant (so called "low-temperature freezing techniques", such as: solid carbon dioxide (SCD) and liquid nitrogen (LN) ground freezing).

The temperature of freeze pipe's wall can reach up to $-40{ }^{\circ} \mathrm{C}$ during "brine" freezing; $78^{\circ} \mathrm{C}$ during SCD freezing; and $-196{ }^{\circ} \mathrm{C}$ during $\mathrm{LN}$ freezing. 


\section{1 "Brine" freezing method}

It utilizes a mechanical refrigeration plant that is designed to cooling liquid coolant. Then this coolant circulates through a pipework system. (Fig. 2). As liquid coolant is commonly used calcium chloride brine, however, several other liquids were proposed, such as: potassium and lithium chloride brines, kerosene, ethanol, methylene chloride [16]; diesel oil fuel, propylene and ethylene glycols [15]; terpene [17]; etc.

A refrigeration plant may consist of one- or two-stage compressors [2]. In the former case the possible temperature of brine is minus $25-30^{\circ} \mathrm{C}$. In the latter, it is drop to minus $40-45$ ${ }^{\circ} \mathrm{C}$.

A mechanical plant requires power and water services, if in a sensitive area, acoustic shrouds to minimize noise disturbance. It usually need a second freezing plant must be kept available on standby for service at short notice. Building the ice-wall may typically take up to three months for urban construction projects.

\subsection{Liquid refrigerant method}

In the capacity of expendable refrigerants are generally used liquids, such as liquid nitrogen or liquid carbon dioxide [2,18].

In this methods no refrigerant plant is needed. Liquide refrigerant is supplied directly into the freeze pipes, which combined in short circles with two to five pipes in a row. After circulating through them, formed gas is released into the atmosphere (fig. 3).

This effectively restricts LN freezing to small-scale exercises or emergency applications during which no more than $200 \mathrm{~m}^{3}$ of soils are frozen $[1,7]$.

\subsection{Solid refrigerant method}

Another possible method of freezing is AGF with using solid carbon dioxide ("dry ice"). One possible scheme of this method is presented in Fig. 4 and 5.

According to [1,19], there are two ways for using solid carbon dioxide.

The first one, solid carbon dioxide is loaded directly into freeze pipes. Carbon dioxide takes heat from the surrounded grounds, and as the result, the refrigerant sublimates. The temperature in freeze pipes is lowered up to $-78.9^{\circ} \mathrm{C}$. Water around them freezes and the icewall is created. Carbon dioxide is regularly loaded into the freeze columns to maintain its level above the water table.

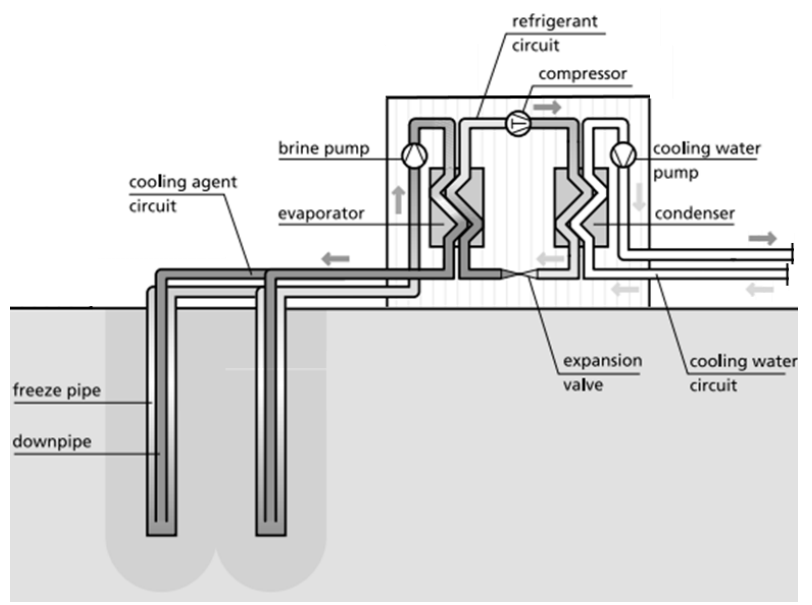

Fig. 2. The "brine" freezing method 


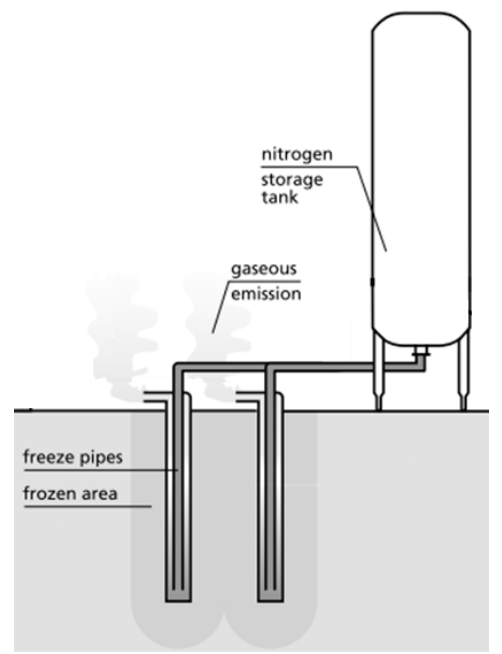

Fig. 3. Liquid nitrogen method of freezing

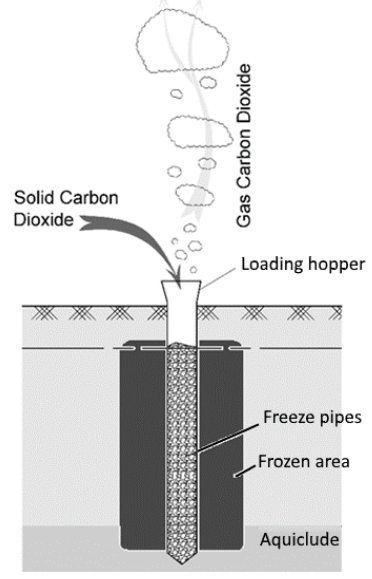

Fig. 4. Solid carbon dioxide method of freezing (a direct method of SCD freezing)

This method has significant advantages: a freezing system has no moving parts, it is silent, and requires no major services, such as water or electricity; refrigeration is fast, typically taking up to one week to form a contiguous ice-wall.

The refrigerant is lost to the atmosphere after only one cycle, as a result the cost of ice formation and its maintenance for lengthy construction works may be excessive.

According to $[1,20]$, this method can replace a brine freezing method with a freezing plant up to $200 \mathrm{~kW}$ power. It does not require water, trained staff for its maintenance. It is not required pipelines on ground surface; therefore, the preparation period is much easier and shorter.

\subsection{Combined method of freezing}

The second way of using solid carbon dioxide in the artificial ground freezing process is using it with a mixing tank and circulating secondary coolant (Fig. 6).

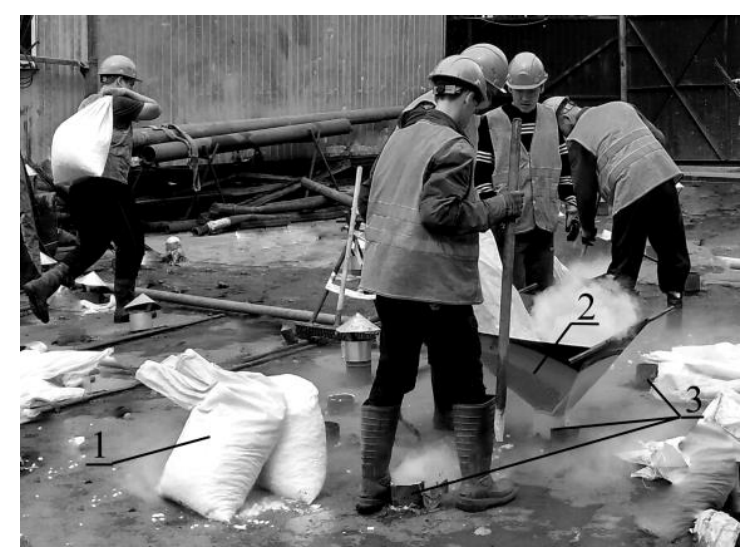

Fig. 5. Solid carbon dioxide ground freezing. 1 - bags with granulated solid carbon dioxide; 2 loading hopper; 3 - well heads of freeze pipes 


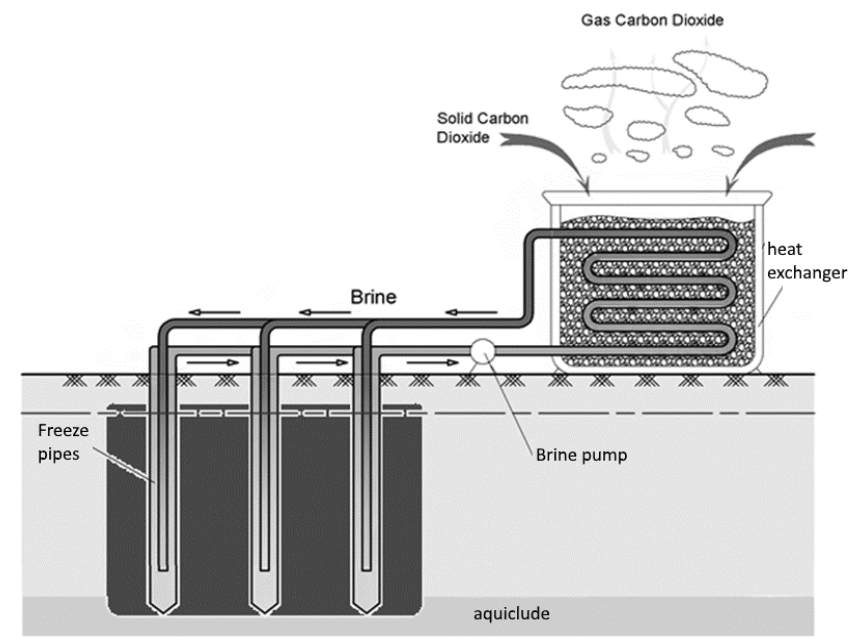

Fig. 6. Method of AGF with using solid carbon dioxide as a second coolant

The heat transports from soils to solid carbon dioxide by heat-transfer liquid. System consists of a mixing tank (a heat exchanger), filled with solid carbon dioxide, and "brine" network. Coil pipes are installed in the tank. The heat-transfer liquid is circulated through these pipes and passes heat to the carbon dioxide, that sublimates after it. The tank is filled with solid carbon dioxide constantly.

This method is a variation of the brine freezing, just with another type of a freezing plant.

As the heat-transfer liquid, any liquid with low freeze temperature can be used. If calcium chloride brine is chosen, the temperature of freeze pipe would be near $-50^{\circ} \mathrm{C}$. If, for example, ethanol, the temperature can be up to $-78.9^{\circ} \mathrm{C}$.

The tank can also be filled with antifreeze liquid to improve heat transfer process [1].

This method has not significant disadvantages. It can be used as a quite effective way of achieving the low temperatures during AGF.

In [20], one new approach for freezing system was proposed (Fig. 7). In this method a mechanical refrigeration plant is combined with a solid carbon dioxide heat exchanger.

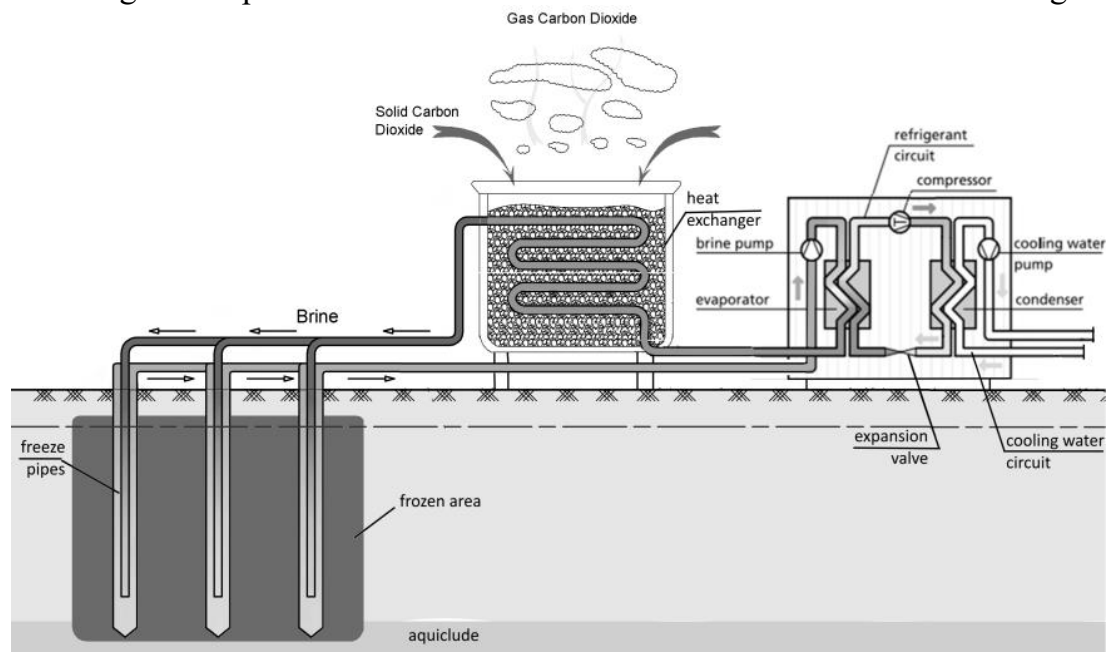

Fig. 7. Combined method of AGF with using a solid carbon dioxide aftercooling heat exchanger 
This additional element allows to increase the power of cooling system and, if it is necessary, to decrease the temperature of liquid coolant. This heat exchanger can be an essential part of a freezing plant during first days of freezing process, when the heat flux to freezing pipes is much higher than the amount of heat that a mechanical refrigeration plant can absorb.

This additional heat exchanger can also be used during the maintenance of ice-wall, when necessary power is much lower than the refrigerator plant can provide. So it can be dismantled and relocated to another construction site.

\section{Discussion}

Different artificial ground freezing methods have their own characteristics and application fields, that were discussed in many studies, for example [2,15,21, etc.].

In table 1, characteristics of freezing methods are presented, based on the classical study [22]. This table also presents the characteristics of solid carbon dioxide freezing methods, that were not discussed before.

Table 1. Characteristics of freezing technics.

\begin{tabular}{|c|c|c|c|c|c|}
\hline & Quality & Brine & $\begin{array}{c}\text { Liquide } \\
\text { Nitrogen }\end{array}$ & $\begin{array}{c}\text { Solid carbon } \\
\text { dioxide }\end{array}$ & $\begin{array}{c}\text { Brine+ solid } \\
\text { carbon dioxide }\end{array}$ \\
\hline \multirow{8}{*}{ 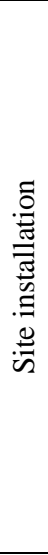 } & electric power & required & not required & not required & $\begin{array}{l}\text { required for a } \\
\text { brine pump }\end{array}$ \\
\hline & water for cooling & required & not required & not required & not required \\
\hline & refrigeration plant & required & not required & not required & not required \\
\hline & storage tank & required & required & not required & required \\
\hline & circulation pumps & required & not required & not required & required \\
\hline & $\begin{array}{c}\text { pipe system for } \\
\text { distribution of } \\
\text { coolant }\end{array}$ & required & not required & not required & required \\
\hline & $\begin{array}{c}\text { low temperature } \\
\text { material for surface } \\
\text { pipes, valves etc. }\end{array}$ & required & required & not required & not required \\
\hline & $\begin{array}{c}\text { low temperature } \\
\text { material for freeze } \\
\text { pipes }\end{array}$ & not required & required & not required & not required \\
\hline \multirow{8}{*}{ 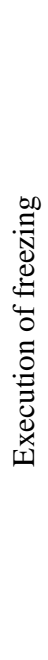 } & $\begin{array}{c}\text { physical condition } \\
\text { of coolant }\end{array}$ & liquid & $\begin{array}{l}\text { liquid/ } \\
\text { vapour }\end{array}$ & solid & liquid \\
\hline & $\begin{array}{c}\text { minimum } \\
\text { temperature } \\
\text { achievable } \\
\text { (theoret.) }\end{array}$ & $\begin{array}{l}-34^{\circ} \mathrm{C} \\
\mathrm{MgCl}_{2} \\
-55^{\circ} \mathrm{C} \\
\mathrm{CaCl}_{2} \\
\end{array}$ & $-196^{\circ} \mathrm{c}$ & $-78.9^{\circ} \mathrm{c}$ & $\begin{array}{c}-55^{\circ} \mathrm{C} \mathrm{CaCl}_{2} \\
-78.9^{\circ} \mathrm{C} \text { ethanol }\end{array}$ \\
\hline & re-use of coolant & standard & impracticable & impracticable & $\begin{array}{c}\text { standard } \\
\text { (impracticable } \\
\text { for refrigerant) }\end{array}$ \\
\hline & control of system & easy & difficult & easy & easy \\
\hline & shape of freeze wall & $\begin{array}{c}\text { great } \\
\text { differences }\end{array}$ & $\begin{array}{c}\text { small } \\
\text { differences }\end{array}$ & $\begin{array}{c}\text { small } \\
\text { differences }\end{array}$ & $\begin{array}{c}\text { small } \\
\text { differences }\end{array}$ \\
\hline & frost penetration & fast & slow & quite fast & quite fast \\
\hline & $\begin{array}{l}\text { impact on freeze } \\
\text { wall in case of } \\
\text { damage to freeze } \\
\text { pipe }\end{array}$ & $\begin{array}{l}\text { thawing } \\
\text { effect }\end{array}$ & none & none & thawing effect \\
\hline & noise & little & none & none & little \\
\hline
\end{tabular}


The significance of these parameters may vary due to economic or regional reasons, as the result, they can be compared only for the location of a construction site and in a particular time moment.

Table 1 shows that the methods with using solid carbon dioxide have significant advantages compare to classical freezing methods. Their site installation is much easier, and as a result, faster. The direct method does not require any installation procedures at all. Freezing process can begin immediately after finishing boring process. If the boring period is long, the freezing can be started just after completion of several freeze pipes.

Nowadays, in Moscow, SCD freezing method fully replace LN freezing. That happened because of several reasons. First, due to more complicated installation process of the LN distribution system, the total freezing period for LN and SCD freezing are approximately the same. Secondly, the cost of LN freezing is much higher. The last and the main reason is that LN freezing is a complicated and dangerous method, that need special cautiousness during the workflow. At the same time, SCD freezing can be realized without any special preparation by unqualified workers (Fig. 5).

\section{Conclusion}

There are several methods of ground freezing. All of them have their own distinguish features. However, not all of them can be used in urban construction works equally effective. The present situation of underground construction works in Moscow does not allow to use LN freezing, as a result SCD freezing has been being used widely. The next step in developing ground freezing method should be developing combined freezing methods, that allow increase freezing rates and lower their costs.

\section{References}

1. M.N. Shuplik, PhD Thesis, (Moscow Mining Institute, 1989)

2. J. S. Harris, Ground freezing in practice (Thomas Telford, 1995)

3. M. Pleshko, A. Pankratenko, A. Revyakin, E. Shchekina, S. Kholodova, E3S Web of Conf., 33, 2036 (2018)

4. G. Romanova, M. Pleshko,M. Rossinskaya, N. Saveleva, A. Pankratenko Advances in Intelligent Systems and Computing, 692, 1111-1124 (2017)

5. N.G. Trupak, Artificial groud freezing during construction of vertical pits (UgleTechIzdat, Moscow, 1954)

6. P. Schmall, A. Dawson, Proc. of the Ins. of Civ.Eng.-Gr. Impr., 170, 159-172 (2017)

7. J. Hu, Y. Liu, Y. Li, K. Yao, J. Civ. Eng. 00, 1-7 (2018)

8. G. Russo, A. Corbo, F. Cavuoto, S. Autuori, Undergr. Sp. Technol., 50, 226-238 (2015)

9. A.Y. Dorman, Artificial ground freezing during construction of underground railway systems (in Russian) (Moscow, Transport, 1971)

10. J. Hu,Y. Liu, H. Wei, K. Yao, W. Wang, Int. J. Geomech. ASCE, 17, 1-11 (2017)

11. A.N. Vulfson, O.O. Borodin, Russ. Meteorol. Hydrol., 34, 491 (2009)

12. L. Han, G. Ye, Y. Li, X. Xia, J. Wang, Can. Geotech. J., 53, 1-10 (2016)

13. A. Marwan, M. M. Zhou, A. M. Zaki, G. Meschke, Comput. Geotech., 75, 112-25 (2016) 
14. S. Huang, Y. Guo, Y. Liu, L. Ke, G. Liu, C. Chen, Appl. Therm. Eng., 135, 43545(2018)

15. O.B. Andersland, B. Ladanyi, Frozen Ground Engineering (Wiley, 2004)

16. V.A. Fedukin, Excavation of vertical shaft pits with artificail ground freezing (in Russian) (Moscow: Nedra, 1968)

17. P. Porcellinis, J.L. Rojo, C. Especiales, Sel. Pap. from the Sec. In. Symp. on Ground Freezing, Trondheim, Norway, 24-26 June 1980 (Elsevier), 28, 203 (2017)

18. N.G. Trupak, Artificial ground freezing in underground construction work (in Russian) (Moscow: Nedra, 1974)

19. J.A. Shuster, Proc. First North American Rapid Excavation and Tunneling Conf., ASCE-AIME, 2, 863-895 (1972)

20. P.V. Nikolaev, PhD Thesis (National University of Science and Technology MISIS, 2016)

21. N.G. Trupak, Artificial ground freezing during construction of underground structures (in Russian) (Moscow: Nedra, 1979)

22. K. Stoss, J.Valk, Eng. Geol., 13, 485-494 (1979) 